\title{
1 Active thermal mass enhancement using 2 phase change materials
}

3

4

5

6

T.R. Whiffena, G. Russell-Smith ${ }^{b}$, S.B. Riffata

a corresponding author: Thomas.whiffen@nottingham.ac.uk, +44(0)115 748 4839, Dept. Architecture and Built Environment, University Of Nottingham, University Park, Nottingham, NG7 2RD, United Kingdom

${ }^{b}$ Actimass Ltd., The Sir Colin Campbell Building, University of Nottingham Innovation Park, Triumph Road, Nottingham, NG7 2TU, United Kingdom

\section{ABSTRACT}

Buildings account for around $40 \%$ of energy consumption in the UK. For over twenty years active thermal mass systems have been a feature in low-energy buildings in northern Europe. By passing ventilation air, and utilising night ventilation, through the hollow core structures efficient heating and cooling has been achieved. Despite the success, such systems suffer from space overheating and efficiency losses during extended hot periods. Control strategies have largely mitigated this effect however low cost retrofit solutions that enhance the system are of interest. This research therefore investigates the benefit of using innovative phase change material (PCM) solutions to enhance thermal comfort and reduced energy usage of traditional active thermal mass systems.

A prototype PCM enhancement was constructed, with energy saving and comfort benefits investigated under controlled laboratory conditions. In absolute terms the PCM solution offered an additional $12.5 \%$ energy storage capacity and a $29 \%$ increase in active surface area, coupled with the existing sensible thermal mass. Under laboratory conditions the PCM addition saved an additional $0.1 \mathrm{kWh}$ per day, delayed AC onset by 1.2 hours and offered an average $1.0^{\circ} \mathrm{C}$ reduction in room temperature during eight hours of fixed cooling load, contrasted against the original active thermal mass system.

\section{KEY WORDS}

Active thermal mass, phase change materials, thermal mass, free cooling, night cooling, energy-efficient cooling 


\section{Introduction}

2

Worldwide, in 2011, 30EJ were consumed within service sector buildings, $26 \%$ of total built environment consumption [1]. Assessing the end-use energy demand in such buildings (Figure 1.1), 33\% of end-use energy was consumed through space heating and cooling. The demand for energy supply continues to rise, putting extra stress on energy markets and the environment, yet the energy intensity (energy consumption divided by contribution to GDP) has not improved since the late 1980s, suggesting a lack of improvement in energyefficiency [2]. To meet the UK government climate change targets (80\% reduction by 2050), energy-efficient measures, throughout the service sector built environment, are essential [3]. Through activation of building thermal mass, space heating and cooling demands can be reduced and offset.

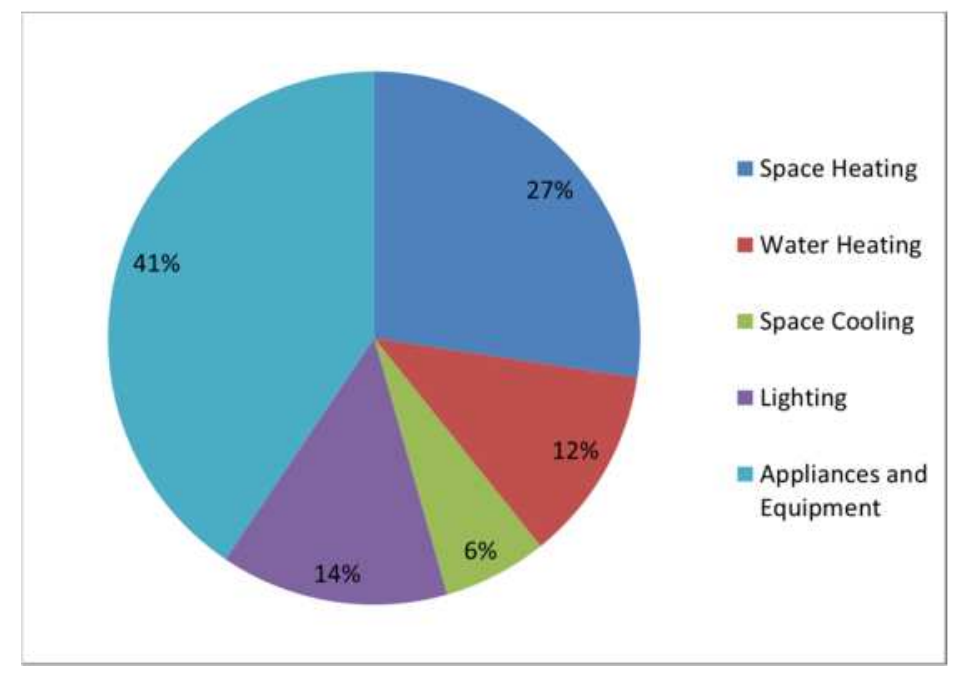

Figure 1.1 - Service-sector Built Environment End-use Energy Breakdown for 2011 [1]

Active thermal mass systems utilise the intrinsic thermal mass of a building by incorporating an air network into the mass. By embedding a fluid network into the thermal mass, the active heat transfer area is increased; improving performance. Further, the conditioning of the air, through connected plant equipment, enables temperature control of the thermal mass [4]. Heat recovery from the exhaust air through a thermal wheel further improves efficiency.

Figure 1.2 demonstrates the temperature fluctuation and operation of the thermal mass in an active thermal mass system. From point (1) to (3) internal gains from occupant behaviour and solar gains accumulate thermal energy in the room, and subsequently in the thermal mass. The thermal mass moderates the temperature by absorbing heat energy at the heat transfer surface. Once unoccupied, the room can be cooled by activating the 

(4) to (5)).

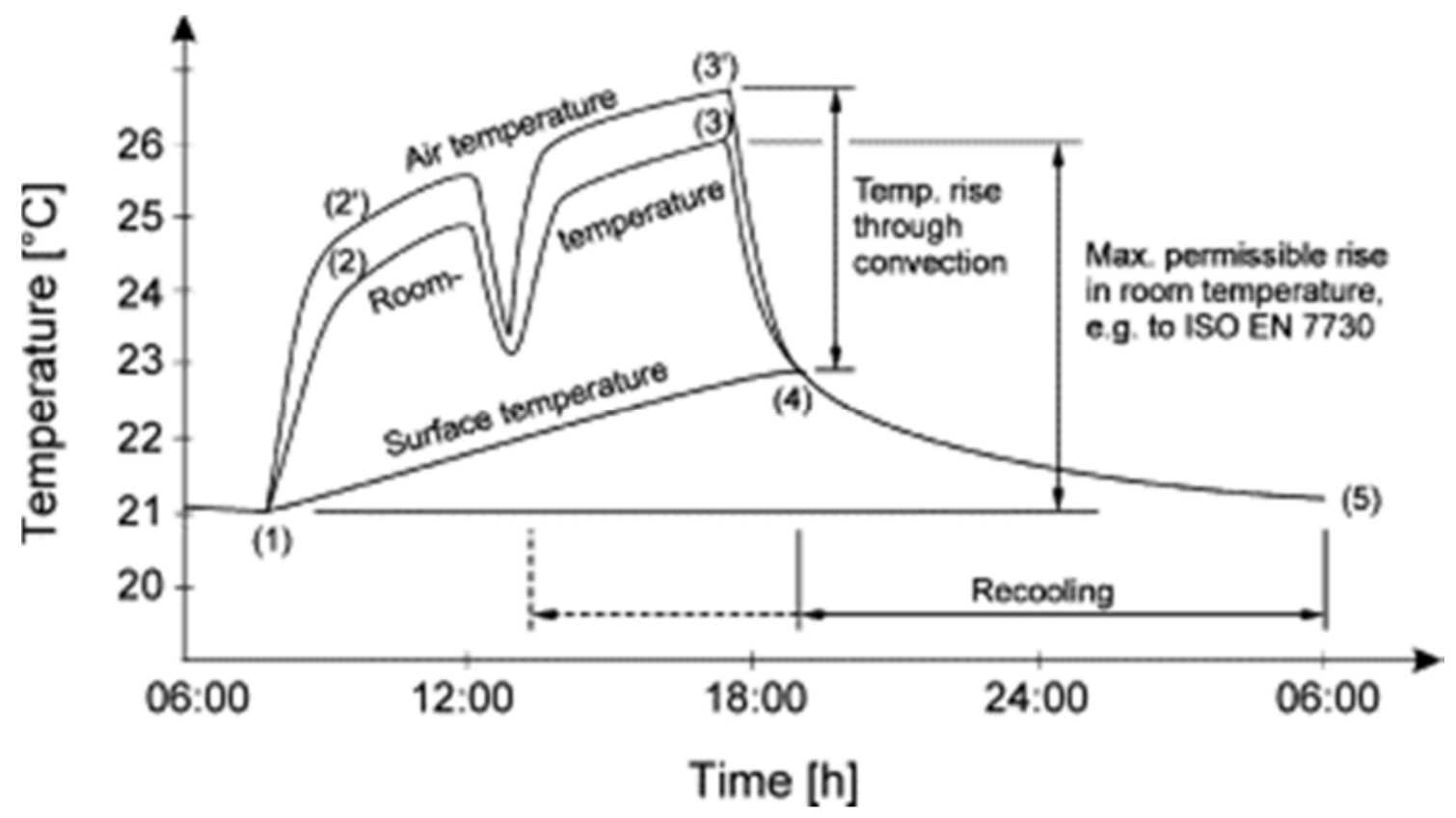

Figure 1.2 - Diurnal temperature cycles for an active thermal mass application [4]

5 The popular Actimass and Termodeck [5] systems utilise ventilation air as the thermal fluid passing through an

6 air network in the hollow core slabs. The concrete hollow core absorbs heat from the room, whilst pre-

7 conditioned ventilation air passes through the hollow core; before being released into the room, as

8 characterised in Figure 1.3. Invented in the late 1970's a steady stream of computational and experimental

9 research has been carried out on the industrial system [6]. 


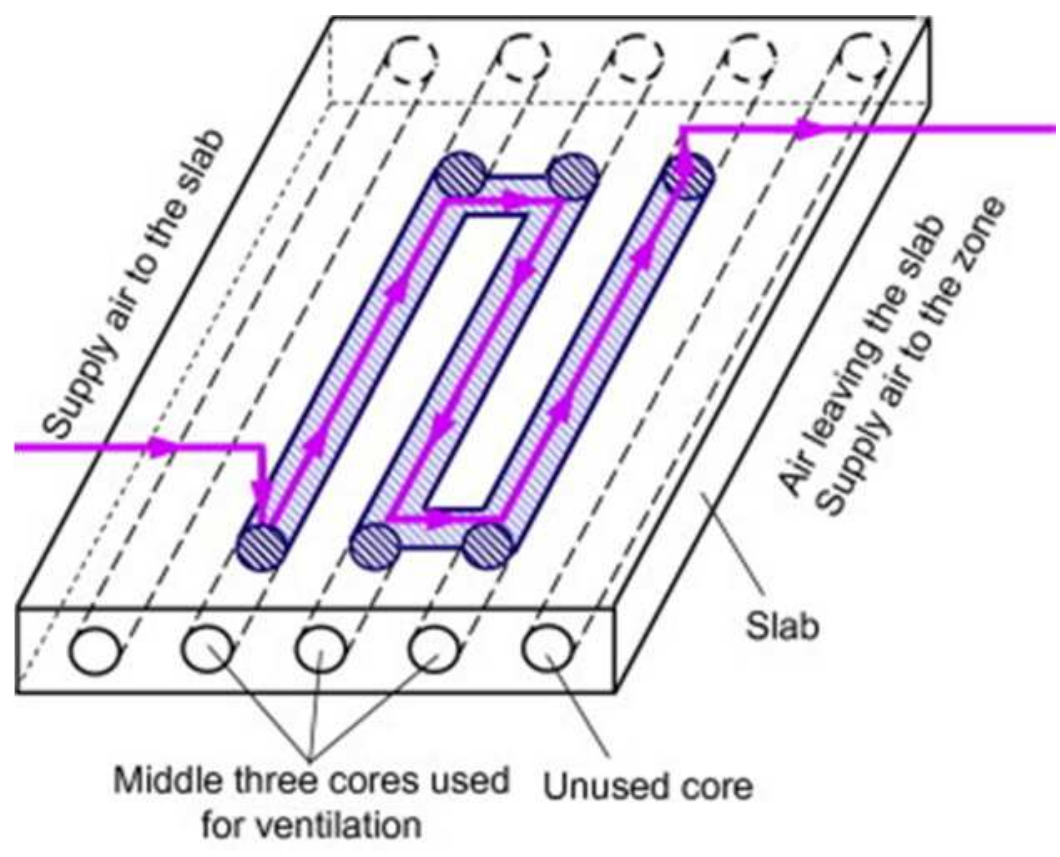

Figure 1.3 - Typical Hollow Core Air Network [6]

The ventilation air serves to maintain hollow core and room temperature. Air passing through the hollow core en-route to the room increases the heat exchange rate through an increase in heat transfer area and forced ventilation, whilst also enabling room temperature control through recycled heat. Heat transfer from the thermal mass to room is no longer limited by the ceiling surface area, since pre-treated ventilation air conditions the room also.

During hot spells night ventilation flushes the residual heat from the hollow core thermal mass. This extends the operation envelope and ensures room temperatures never exceed the national standard office temperature hours [7]. Night ventilation operation limits the applicability of the technology to buildings with intermittent occupancy patterns. The temperature profiles, in Figure 1.4, demonstrate the twenty-four hour operation the ventilated TES undertakes; maintaining comfort temperatures during occupied hours, and then discharging the thermal energy stored during night hours. 


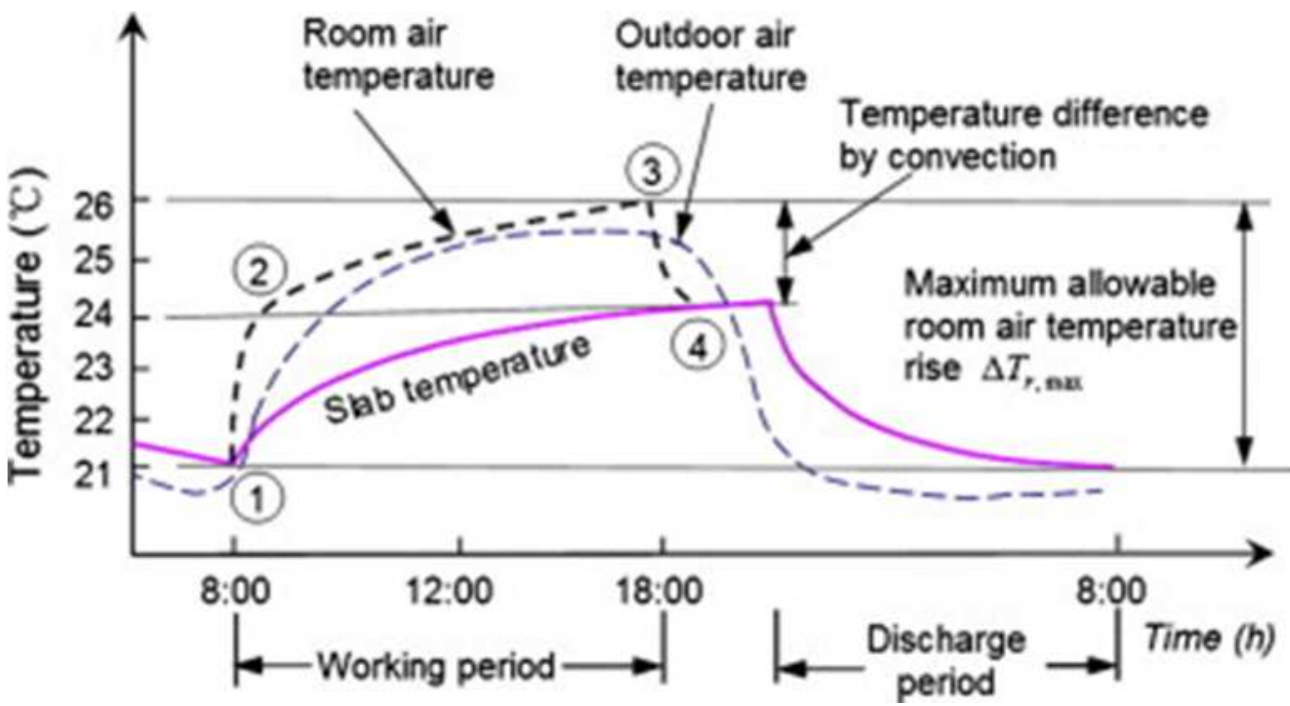

Figure 1.4 - 24hr Hollow Core Operation [6]

Commercial studies, to date, have focussed on building performance reviews; whilst most academic interest has sought to characterise performance through computational modelling. Ren [8] used a simplified-combinedresistance or lumped-parameter method to model the hollow core network. The work suggested that the heat transfer coefficient around the bend in the air network was fifty times greater than in the straight duct. However modelling by Barton [9], using a two-dimensional finite-difference model, found minimal effect on overall heat transfer due to the air network bends. Suggestion by Green [10] of additional internal baffles, to enhance heat transfer, was made following validated CFD and laboratory investigations on a two-core test slab.

A three-year investigation by Winwood $[5,11,12]$ used a CFD model of the hollow core to characterise the performance under ventilated conditions. The work culminated in a full building assessment offering suggestions to improve the building's poor annual operation [11]. The problems noted inappropriate control, which significantly hindered building energy reduction. To improve the active thermal mass system variable-speed fans with high efficiencies was suggested. Additionally, the monitoring also revealed that during hot periods, where ambient temperature was too high to achieve night cooling, little could be done except to switch off night ventilation and wait for the next cool night. This hindrance highlighted the need to maximise the energy storage capacity in the active thermal mass system and improve predictive control mechanisms that minimise daily temperature gain in the thermal mass.

Since Winwood's monitoring and analysis the control system and plant design of active thermal mass buildings have been developed, ensuring target temperatures are maintained through the majority of the year. 
1 Traditionally additional chiller capacity in the plant is designed to satisfy peak cooling demand. The addition of

2 further thermal mass may offer a low energy alternative to chiller reliance. Based on European climate data,

3 free cooling via night ventilation is available through ninety-six percent of the year [13]. Although inhibiting to active thermal mass efficiencies the occurrence of peak periods without available night cooling are rare in the UK. The work presented, in part, investigates whether additional latent thermal mass can mitigate saturation temperatures during peak cooling load periods. Phase change material (PCM) addition, with specific melt temperature, was used to increase the energy storage capacity of active thermal mass systems during temperature operating regions where overheating threatened. Further, since peak periods account for less than four percent of UK weather the work considered the benefit of PCM addition to a typical active thermal mass system under typical free cooling conditions. Expected energy savings were investigated as well as thermal comfort benefits.

PCM offers viable lightweight thermal energy storage (TES) solutions for energy savings within the built environment. Theoretically, PCM is capable of up to fifty times the energy storage density as concrete, assuming all mass is evenly heated over a five kelvin range that includes the PCM melt temperature (Figure 1.5). Applications of PCM as energy saving systems within the built environment vary from impregnated wall-board, insulation sheets and PCM incorporated concrete [14]. 


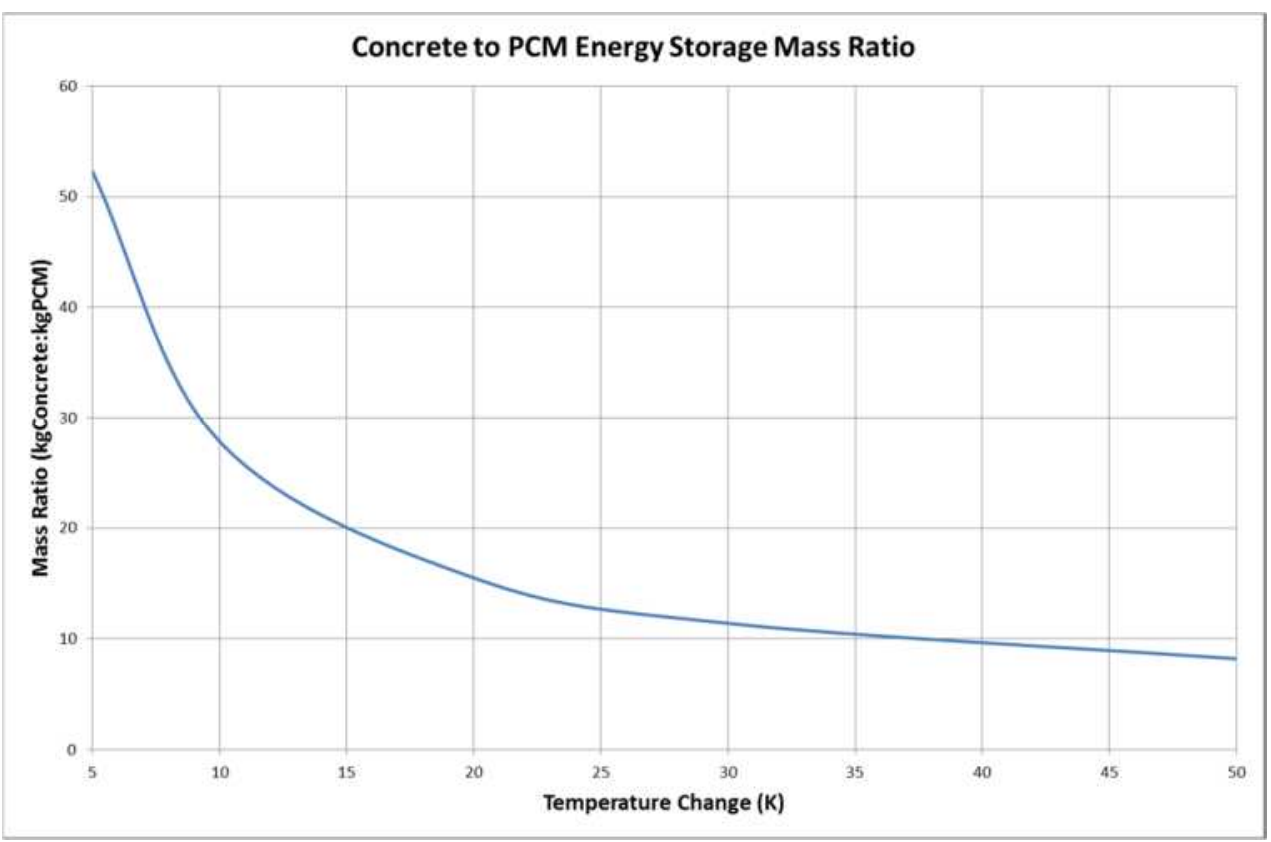

Figure 1.5 - Variation of Concrete to A22H PCM mass ratio with respect to thermal mass temperature change

PCM enhancement to concrete has long been studied. Three common methods for incorporating the PCM have been investigated [15]:

1) Immersion $[16,17]$ : the solid concrete is immersed in liquid PCM causing PCM to solidify in the concrete pores.

2) Impregnation $[18,19]$ : prepared porous aggregates are immersed in PCM liquid and allowed to cool. Following saturation the PCM loaded aggregates are added to the concrete mix.

3) Direct mixing $[18,20]$ : the PCM is pre-encapsulated in microscopic capsules. The microencapsulated PCM is subsequently mixed directly into the concrete mix.

From these methods both immersion and impregnation suffer from PCM leakage, inhibiting applications. Direct mixing methods make use of microencapsulated PCM to avoid PCM leakage during their melt phase.

Additionally to the generic methods of PCM application to concrete outlined above, further research [21] sought to optimise use of PCM in a thermally active building system (TABS). In the TABS a layer of PCM-concrete was cast onto the ceiling soffit of prefabricated TABS. The investigation tested zero to six weight percent PCMconcrete mixes. Direct mixing using microencapsulated PCM was used. This method benefits from easy mixing and application whilst avoiding leakage. Total levels of PCM however are limited based on the percentage of PCM in the concrete to maintain strength in the concrete mix [20]. 
1 Further, the investigation found that PCM addition to the concrete soffit inhibited the heat transfer from the

2 TABS since the PCM-concrete layer had a lower thermal conductivity than pure concrete. For effective use of

3 active thermal mass systems exposure of the soffit is paramount. Any further development of a PCM-concrete active thermal mass system must consider the positioning of the PCM to maximise the latent benefits without inhibiting the sensible thermal mass aspects. The PCM system investigated in this work has been designed with retrofit of active thermal mass systems in mind; therefore both a pilot-scale active thermal mass system and a prototype PCM system were designed, built and tested to maintain an exposed soffit and maximise the active heat transfer surface. The key outputs monitored are:

- temperature reduction,

- temperature offset,

- energy savings,

- $\quad$ and daily average cooling efficiency. 


\section{$1 \quad 2$ Background work}

Prior to the laboratory investigation the pilot-scale active thermal mass system (hollow core) was modelled, designed, built and installed into the test chamber. Additionally the PCM system prototype was modelled, designed, built and installed.

\subsection{Test facility}

The hollow core and PCM systems were installed into a purpose built test facility at the University of Nottingham. The facility consisted of two comparable chambers (Room A and B), with a floor area of $4.3 m^{2}$. Each chamber was fitted with a heat pump air conditioning (AC) system providing mechanically ventilated air into the space. K-type thermocouples were installed into both chambers to monitor room temperature.

The thermal mass system was installed into Room A, in addition to the AC system. Room B featured no thermal mass and was conditioned using save for the AC system alone, and acted as a reference chamber to track performance of the thermal mass system against. Power meters were fitted to the variable speed fan and AC systems in both Room A and B to record energy consumption. Radiant heat mats were installed into both chambers to mimic internal cooling loads.

\subsection{Hollow core}

The pilot-scale hollow core system was constructed from an exhibition sample measuring 1.2 by 1.5 meters, with a depth of 0.325 meters. The sample was made up of six cores, four of which running the length of the sample and two running three quarters of the length. An air network was prepared by drilling 125 millimetre cross-overs and a 125 millimetre outlet as shown in Figure 2.1. The air network had an approximate active surface area of $3.8 \mathrm{~m}^{2}$, more than two hundred percent greater than the soffit surface area alone. K-type thermocouples were suspended throughout the air network and embedded in the slab, 40 to 70 millimetres from the soffit surface. Additional concrete (40 to 70 millimetres deep) was laid to embed the sensors giving a total sample depth of approximately 0.375 metres. The exposed cores were sealed using wooden boards and a variable-speed fan was fitted to the hollow core network inlet. 


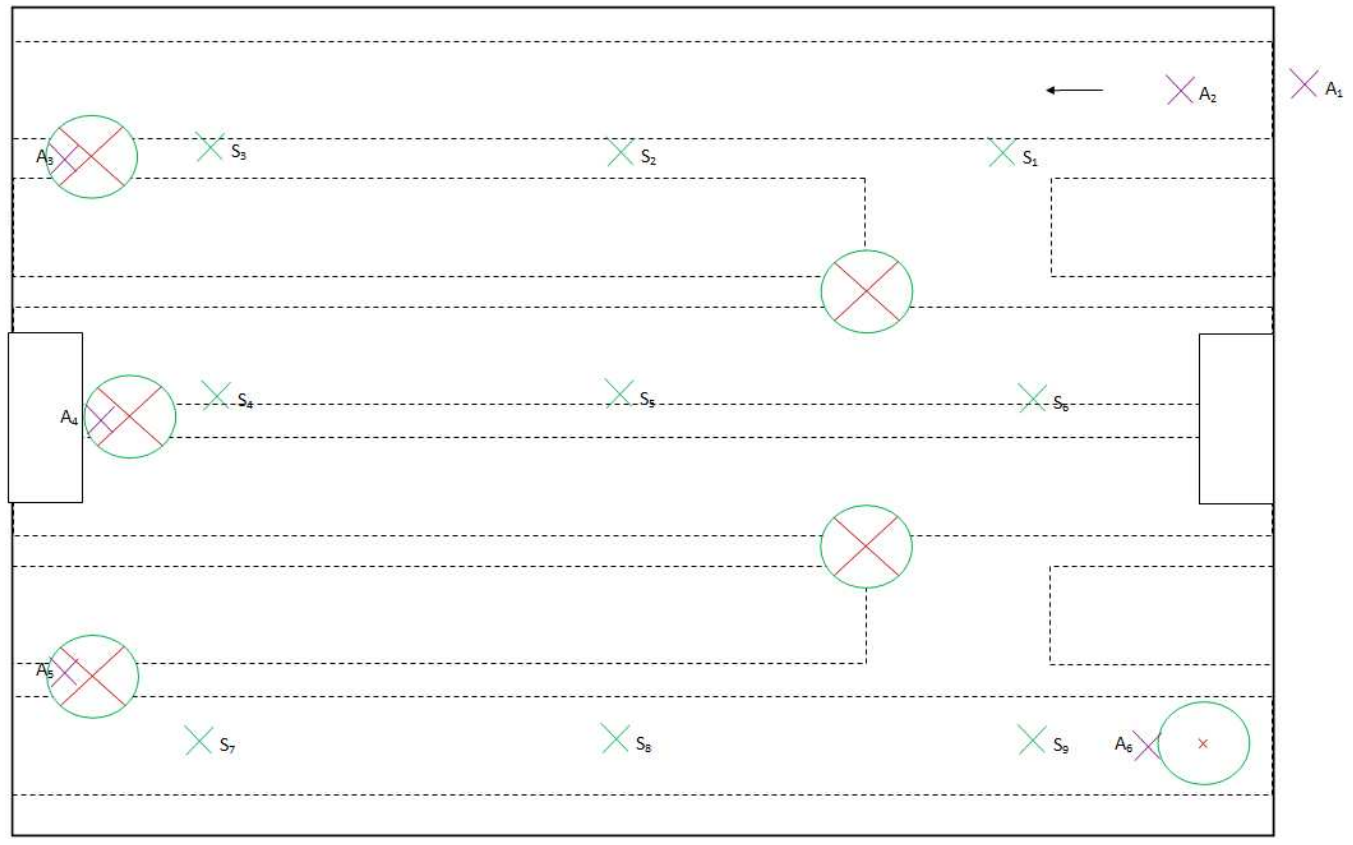

3 The sample, weighing 1.27 tonnes, was raised 2.1 metres above chamber floor level on a purpose built steel box

4 frame. The hollow core and frame were wheeled into the chamber. Subsequently the chamber floor and final

5 wall was constructed around the hollow core sample. The air network and thermocouples were connected.

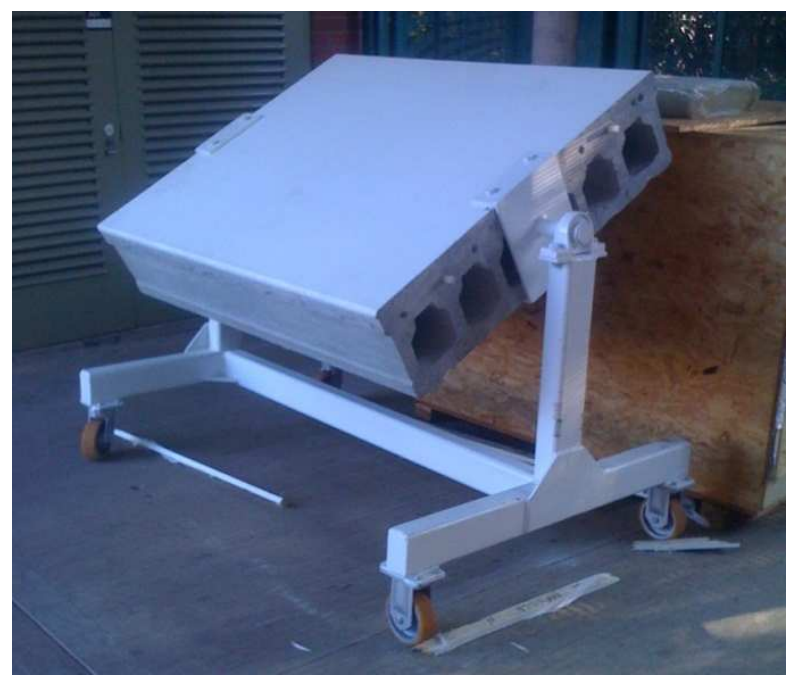




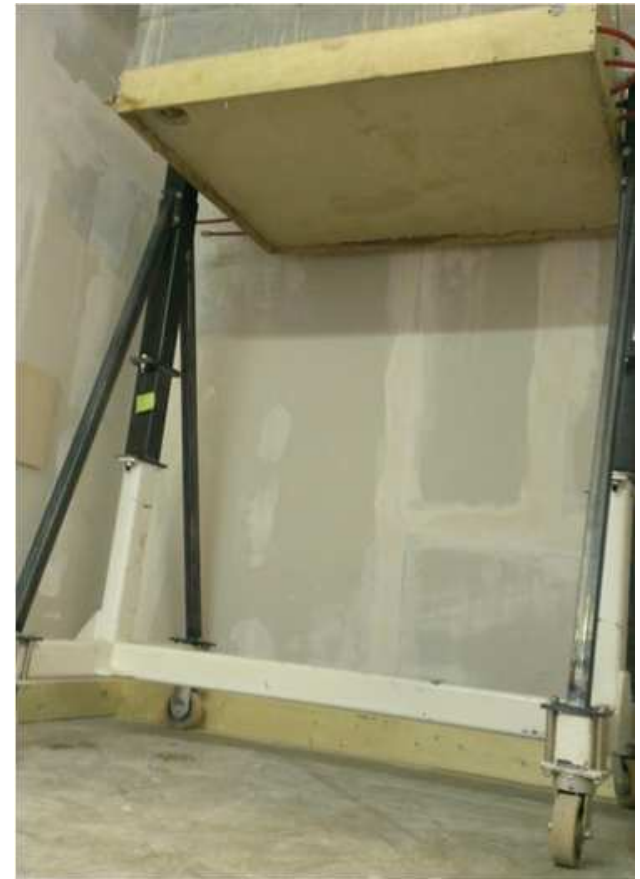

Figure 2.3 - Installed hollow core sample

\subsection{PCM system}

4 The PCM system container was constructed from three millimetre aluminium sheeting and honeycomb. The

5 system contained 7.5 kilograms of PCM with an average melt temperature of $24.5^{\circ} \mathrm{C}$ and laboratory measured

6 latent heat of $164.6 \mathrm{~kJ} / \mathrm{kg}$. The PCM was selected based on cost benefit analysis and to offer latent cooling

7 benefits when slab overheating threatened. The PCM system was retrofitted as part of the hollow core sample,

8 adding approximately 12.5 percent of thermal energy storage capacity and increasing the active surface area by 9 twenty-nine percent. 


\section{$1 \quad 3$ Method}

2 To determine the thermal (temperature reduction) and energy saving benefits (temperature offset, measured energy savings and daily average cooling efficiency) of the thermal mass technologies investigated combined chamber tests were designed and conducted. The hollow core and PCM system were fitted into the thermal mass chamber. Both the thermal mass and reference chambers were fitted with AC units, to thermo-regulate the chambers, and a heat mat, to mimic internal gains.

Fixed occupancy, peak period and diurnal swing tests were conducted in the chambers to determine the energy

8

\begin{tabular}{|c|c|c|c|}
\hline & & Reference & Thermal Mass \\
\hline & Scenario & Chamber & Chamber \\
\hline a. & AC schedule & $8 \mathrm{hrs}(9.30-5.30)$ & $8 \mathrm{hrs}(9.30-5.30)$ \\
\hline b. & AC Setup & Cool to $24^{\circ} \mathrm{C}$ & Cool to $24^{\circ} \mathrm{C}$ \\
\hline c. & Fan Setup & N/A & $32 \mathrm{~W}$ Fan from $22^{\circ} \mathrm{C}$ \\
\hline \multirow{2}{*}{ d. } & Occupancy (Heater) & 8 hrs (9-5)on, & 8 hrs (9-5)on, \\
\hline & Schedule & off for $16 \mathrm{hrs}$ & off for $16 \mathrm{hrs}$ \\
\hline \multirow{3}{*}{ e. } & & $50 W / m^{2}$ & $50 W / m^{2}$ \\
\hline & Heater Load & & \\
\hline & Ventilation & & \\
\hline \multirow[t]{2}{*}{ f. } & & N/A & $32 \mathrm{~W}$ Fan from $22^{\circ} \mathrm{C}$ \\
\hline & Strategy & & \\
\hline
\end{tabular}




\begin{tabular}{|c|c|c|c|}
\hline & & Reference & Thermal Mass \\
\hline & Scenario & Chamber & Chamber \\
\hline a. & AC schedule & $8 \mathrm{hrs}(9.30-5.30)$ & $8 \mathrm{hrs}(9.30-5.30)$ \\
\hline b. & AC Setup & Cool to $24^{\circ} \mathrm{C}$ & Cool to $24^{\circ} \mathrm{C}$ \\
\hline c. & Fan Setup & N/A & $\begin{array}{c}32 \mathrm{~W} \text { Fan from } 22^{\circ} \mathrm{C} \text { for } \\
\text { 8.5hrs }\end{array}$ \\
\hline d. & $\begin{array}{l}\text { Occupancy (Heater) } \\
\text { Schedule }\end{array}$ & $\begin{array}{c}\text { 8hrs (9-5)on, off for } \\
\text { 16hrs }\end{array}$ & $\begin{array}{c}\text { 8hrs (9-5)on, off for } \\
\text { 16hrs }\end{array}$ \\
\hline e. & Heater Load & $50 \mathrm{~W} / \mathrm{m}^{2}$ & $50 \mathrm{~W} / \mathrm{m}^{2}$ \\
\hline f. & $\begin{array}{l}\text { Night Ventilation } \\
\text { Strategy }\end{array}$ & $\begin{array}{l}\text { AC Cool to } 18^{\circ} \mathrm{C} \text { for } \\
12 \text { hours }(6 p m-6 a m)\end{array}$ & $\begin{array}{l}\text { AC Cool to } 18^{\circ} \mathrm{C} \text { for } \\
12 \text { hours }(6 \mathrm{pm}-6 a m)\end{array}$ \\
\hline
\end{tabular}

\begin{tabular}{|c|c|c|c|}
\hline & & Reference & Thermal Mass \\
\hline & Scenario & Chamber & Chamber \\
\hline a. & AC schedule & Off & Off \\
\hline b. & AC Setup & N/A & N/A \\
\hline c. & Fan Setup & N/A & 32 W Fan \\
\hline d. & $\begin{array}{l}\text { Occupancy (Heater) } \\
\text { Schedule }\end{array}$ & $12 \mathrm{hrs}$ On & $12 \mathrm{hrs}$ On \\
\hline e. & Heater Load & $50 W / m^{2}$ & $50 \mathrm{~W} / \mathrm{m}^{2}$ \\
\hline f. & $\begin{array}{l}\text { Night Ventilation } \\
\text { Strategy }\end{array}$ & None & None \\
\hline
\end{tabular}

4 Throughout the chamber tests temperatures and energy consumption were monitored. The peak period 5 conditions represent the times when no night cooling (free cooling) is available and active thermal mass typically 6 overheats [11]. The diurnal swing conditions used an AC schedule to generate night cooling. Energy usage during 
1 this period was not monitored to represent free night cooling. The fixed occupancy conditions were used to 2 observe temperature savings achieved by the enhanced system. During the diurnal swing and peak period tests

3 the $\mathrm{AC}$ cooling strategy was initiated when room temperatures exceeded $24^{\circ} \mathrm{C}$. This strategy was used to maintain comfort temperatures within each space, however, due to the PCM melt temperature $\left(24.5^{\circ} \mathrm{C}\right)$ it is understood that by initiating the AC unit before the majority of PCM has melted the associated energy savings available will not be maximised. 


\section{Results and Discussion}

2 Temperature profiles for the first forty-eight hours under peak period conditions are presented in Figure 4.1

3 along with the office comfort temperatures, based on a clo figure of 1.0 [22]. The solid lines plot the average

4 temperatures in Room A. AC usage can be identified through sudden peaks and troughs in the room temperature

5 data. In both cases the VHC and VPHC systems failed to maintain comfort temperatures into the second day

6 without assistance from the AC unit. Significant night time cooling was required for the VPHC system to maintain

7 the room temperature at $24^{\circ} \mathrm{C}$. This was due to the melt temperature of the PCM inhibiting the natural cooling

8 of the room and the high ambient temperatures throughout the night. 


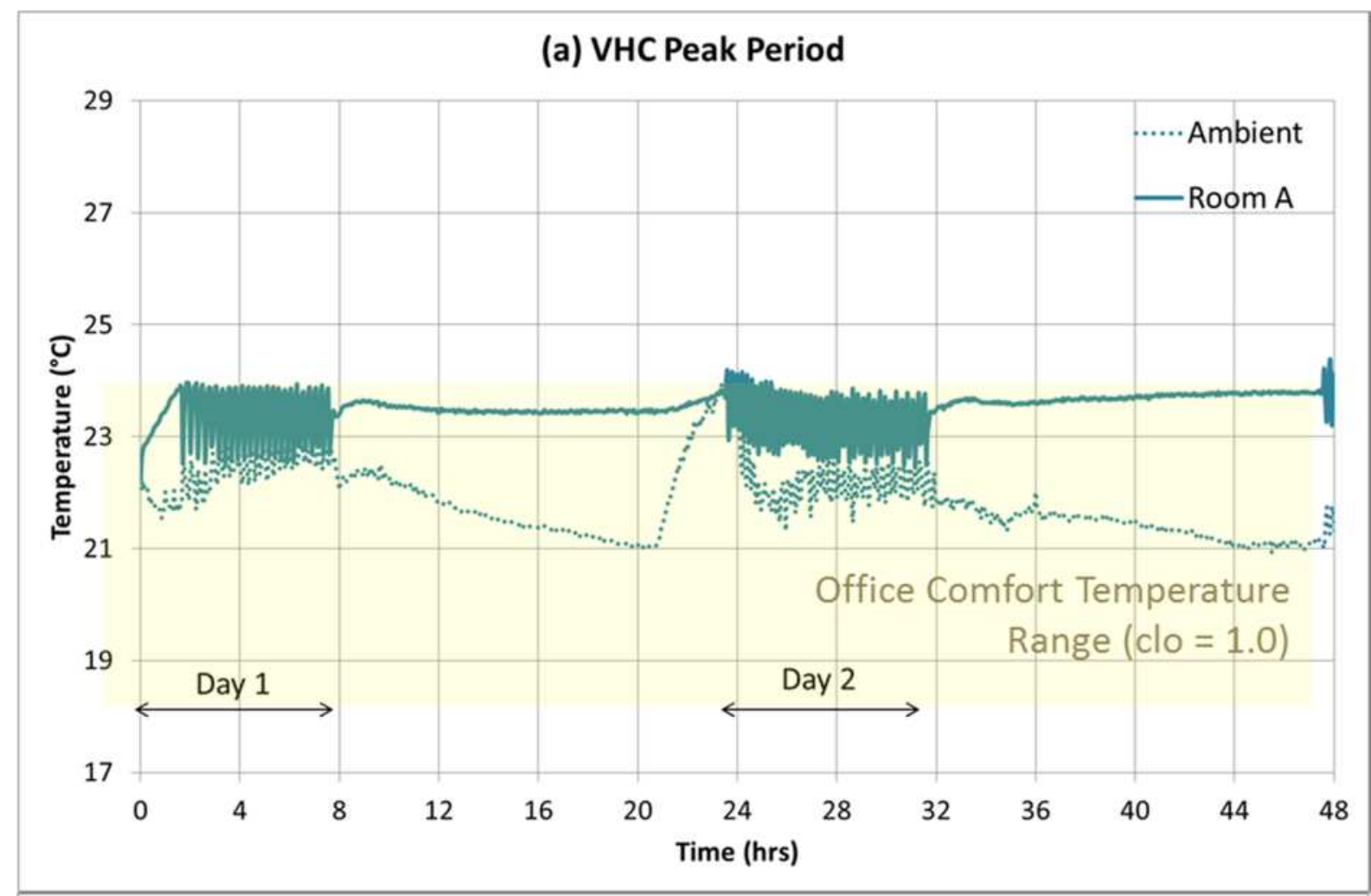

(b) VPHC Peak Period

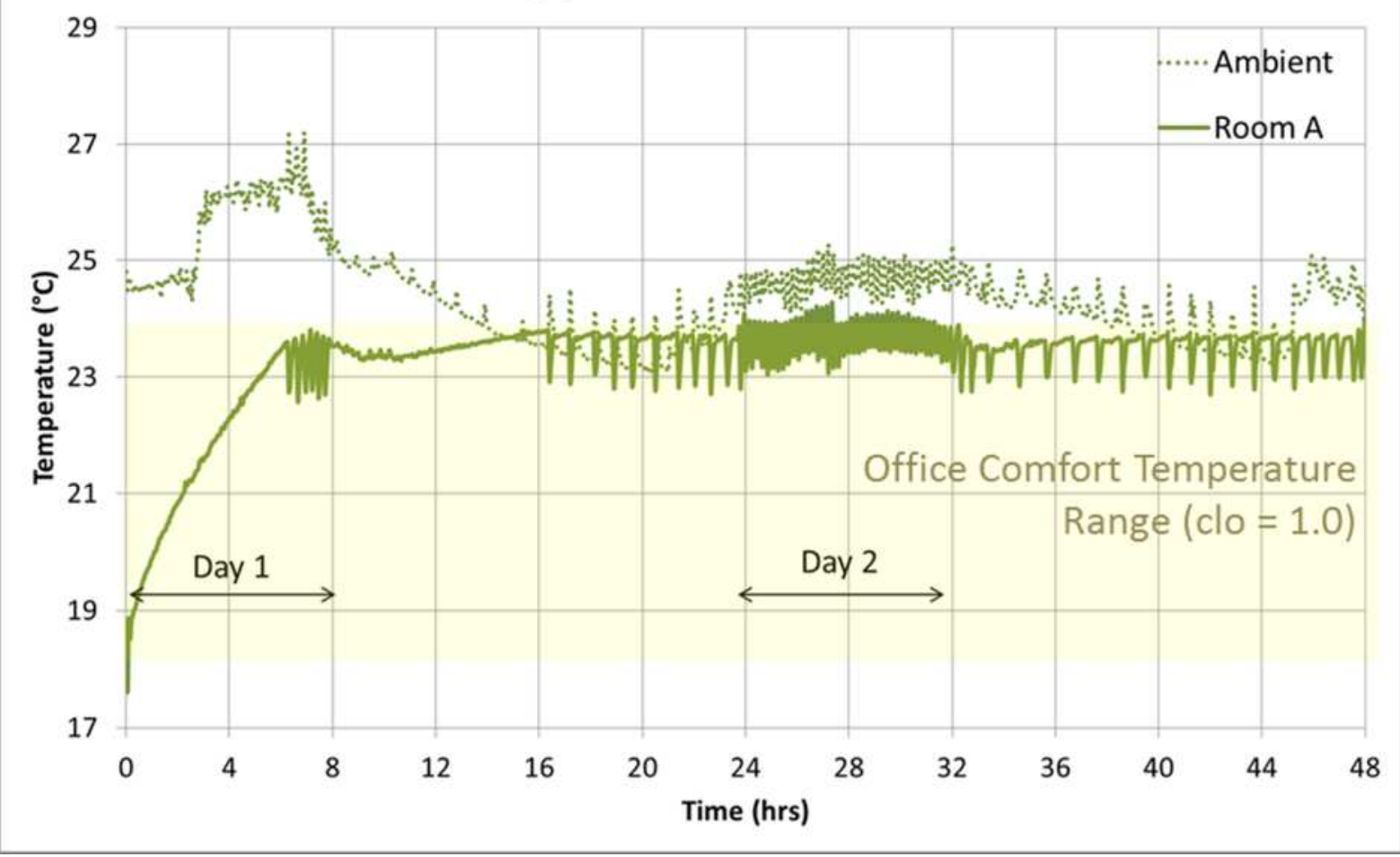

2 Figure 4.1 - 48 hour Ambient and Room A temperature profiles under peak period conditions

3 Diurnal swing conditions were investigated to observe the benefits of the PCM addition when free cooling was available. The temperature profile plots for the first forty-eight hours for both the VHC and VPHC systems are displayed in Figure 4.2 along with the office comfort temperatures, based on a clo figure of 1.0 [22]. During the 
1 night cooling period (between the hours of eight and twenty, and, thirty-three and forty-five) the AC system and

2 fan power was not monitored by the power meter to represent free cooling. The energy usage per day (kWh) in

3 Table 6 and daily average cooling efficiency figures (Table 8) accounted for operation during the heated period 4 only.

5 Evidence from the Room A temperature profiles for both VHC and VPHC systems demonstrates peak temperature delay during both of the 'occupied' heated day periods (zero to eight hours and twenty-four to

7 thirty-two hours). This demonstrates that the free night cooling was sufficient to cool the thermal mass. 


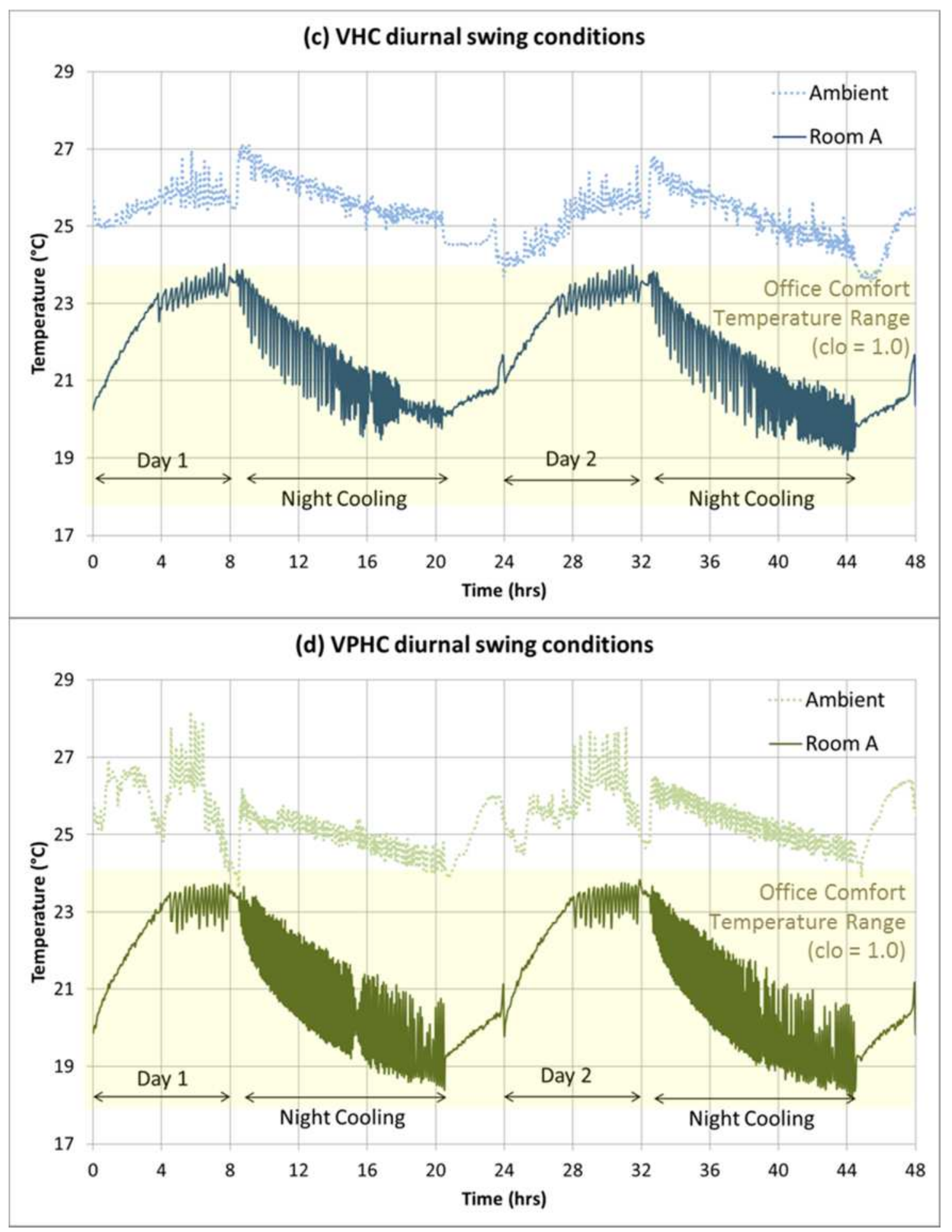




\subsection{Temperature reduction}

2 The temperature reduction represents the additional cooling achieved in the room due to the active thermal mass systems. To assess the temperature reduction benefits of the PCM active thermal mass system enhancement, the results from the fixed occupancy test were assessed.

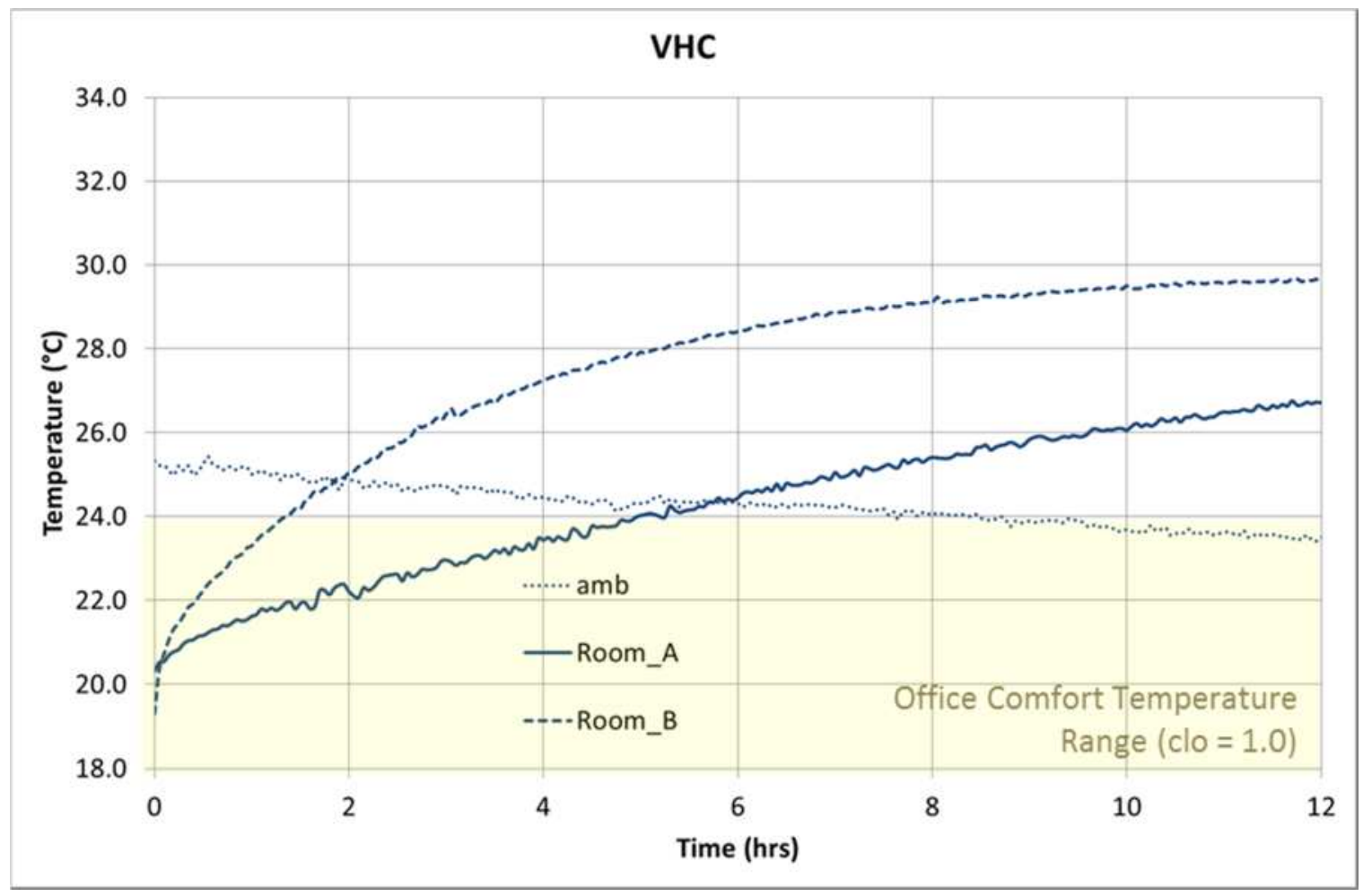




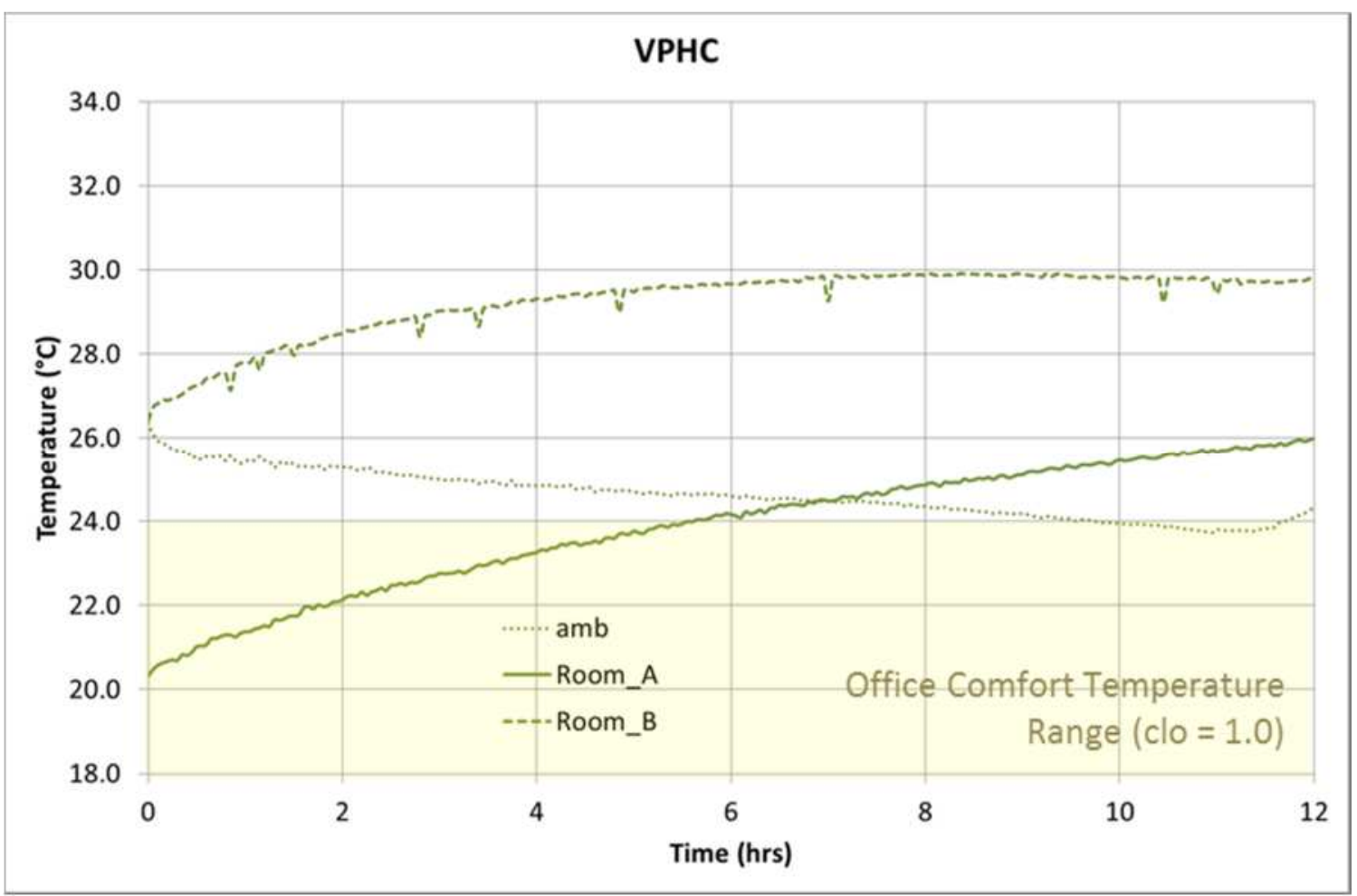

Table 4 - Temperatures after 8 hours under $50 \mathrm{~W} / \mathrm{m}^{2}$ Load

\begin{tabular}{lcc}
\hline & VHC & VPHC \\
\hline Ambient & ${ }^{\circ} \mathrm{C}$ & ${ }^{\circ} \mathrm{C}$ \\
\hline Room A & 24.1 & 24.3 \\
\hline Room B & 25.4 & 24.9 \\
\hline A-B & 29.1 & 29.9 \\
\hline
\end{tabular}

4 The temperature against time plots (Figure 4.3 and Figure 4.4) plot the laboratory, the thermal mass chamber

5 (Room A) and reference chamber (Room B) temperatures for the twelve hour long tests. An internal load of $650 \mathrm{~W} / \mathrm{m}^{2}$ was applied throughout the duration of the test. Figures in Table 4 were taken from the profiles in

7 Figure 4.3 and Figure 4.4 after eight hours of fixed occupancy heating. The VPHC system reduced Room A

8 temperature by $0.5^{\circ} \mathrm{C}$ against the VHC scenario. In commercial projects temperatures are designed to remain

9 below $25^{\circ} \mathrm{C}$ during peak periods. 

$24^{\circ} \mathrm{C}$ the rate of temperature increase in Room A reduces in the VPHC case. At its most extreme this deflection, caused by the melting PCM achieves a $0.9^{\circ} \mathrm{C}$ reduction in average room temperature. At the end of the twelve hours the VPHC Room A temperature was $0.7^{\circ} \mathrm{C}$ below that of the VHC system.

To further assess the temperature savings the average occupied temperature difference was calculated. During the fixed occupancy conditions the temperature saving benefit was observed. The differences in ambient and reference temperatures were accounted for. Under these conditions the VPHC demonstrated an average $1.0^{\circ} \mathrm{C}$ improvement respectively, against the VHC system. Therefore, where no backup AC system is present, VPHC systems will offer greater comfort during hot periods.

\subsection{Temperature delay}

The temperature delay represents the additional time the taken for the thermal mass chamber (Room A) to reach peak temperature compared to the reference chamber. A peak temperature of $24^{\circ} \mathrm{C}$ was used since once this temperature was exceeded the AC was initiated to maintain comfort conditions. Any temperature delay achieved by the VHC or VPHC systems would therefore constitute energy savings to the building user by reducing the electrical demand from the AC system. To determine the temperature delay the temperature profiles from the first day of the peak period tests were observed. In Table 5 the peak delay was calculated as the time taken to go from $22^{\circ} \mathrm{C}$ to $24^{\circ} \mathrm{C}$.

Table 5 - Day 1 peak temperature delay under peak period conditions

\begin{tabular}{llll}
\hline & & VHC & VPHC \\
\hline A: Peak Temperature & Hours & 1.7 & 2.7 \\
Delay & & & \\
B: Peak Temperature & Hours & 0.9 & 0.7 \\
Delay & & & \\
A-B: Peak Temperature & Hours & 0.8 & 2.0 \\
Delay Difference & & & \\
\hline
\end{tabular}


B. Comparatively the VPHC system delayed AC onset by 2.0 hours against Room B, 1.2 hours longer than the VHC system.

The temperature profile (Figure 4.1) demonstrates that overnight the slab remains at a high temperature, therefore no cooling capacity is replenished in the slab. Consequentially no peak delay is evident in day two. Contrastingly, the diurnal swing temperature profile (Figure 4.2) demonstrates that the cooling capacity of both systems was replenished during the night and utilised during the first half of each day. The VPHC system increases the peak temperature delay by up to one hour per day under diurnal swing conditions.

\section{$9 \quad 4.3 \quad$ Energy Savings}

The energy consumption figures for Room A and B in Table 6 were gathered from data collected by the power meters in each chamber. The total energy consumption recorded has been converted into a kWh per day figure. (kWh) minus Room B energy consumption (kWh).

Table 6 - Energy usage under peak and diurnal swing conditions

\begin{tabular}{lcccc}
\hline & VHC & VPHC & VHC & VPHC \\
& Peak Period & Peak Period & Diurnal Swing & Diurnal swing \\
\hline A: Energy usage per day & 3.2 & 4.2 & 1.5 & 1.4 \\
(kWh) & & & & 2.2 \\
B: Energy usage per day & 2.2 & 3.4 & 1.8 & \\
(kWh) & & & & -0.8 \\
A - B: Energy difference & 1.0 & 0.8 & -0.3 & \\
per day (kWh) & & & & \\
\hline
\end{tabular}

During the peak period conditions the active thermal mass system, VHC, required an additional $1.0 \mathrm{kWh}$ per day more than the reference chamber (Room B). Although energy savings were observed in day one, subsequent days, following nights without free cooling, required additional AC cooling during the occupied day. This was in line with work conducted by Winwood [11]. In an effort to increase the thermal mass capacity, whilst reducing energy consumption, and minimise room overheating the VPHC system, featuring additional PCM thermal mass 
was tested under peak period conditions. As with the VHC system, the absence of free night cooling limited the thermal mass cooling effect to the first day. Following the first warm night additional cooling of $0.8 \mathrm{kWh}$ were required to maintain comfort temperatures in Room A, compared to Room B. The VPHC system used $0.2 \mathrm{kWh}$ per day less than the VHC system under peak period conditions.

The figures in Table 6 demonstrate that under synthesised free cooling diurnal swing conditions, 1.7 and 2.8 kWh per day less energy was used to maintain comfort conditions than under the peak period conditions, for the VHC and VPHC systems respectively. The VPHC system saved $0.1 \mathrm{kWh}$ per day, based on Room A energy usage, against the VHC usage; however saved $0.8 \mathrm{kWh}$ per day, $0.5 \mathrm{kWh}$ more than the VHC system's savings of $0.3 \mathrm{kWh}$ per day, based on the relative difference between Room A and B energy usage.

The lack of energy savings under peak period conditions was due to the thermal mass acting as a storage heater into the day two 'occupied' period and beyond. Without free night cooling during subsequent nights there was insufficient capacity in the system to provide cooling from the thermal mass. The additional PCM exacerbated the problem, adding further mass to act as a storage heater throughout night and day ('occupied') periods.

Under diurnal swing conditions the energy saving benefits of the VPHC system were demonstrated. The additional thermal mass increases the cooling capacity of the system, postponing AC usage and thus saving energy through 'occupied' hours. The VPHC system offered a $0.1 \mathrm{kWh}$ per day improvement on the VHC performance (based on the VPHC to VHC Room A usage difference in Table 6). This translates to a 7\% saving, from an additional $12.5 \%$ thermal capacity. This under performance is likely due to the PCM not fully melting during the 'occupied' period. With an average melt temperature of $24.5^{\circ} \mathrm{C}$, above the $\mathrm{AC}$ onset temperature of $24^{\circ} \mathrm{C}$, the full capacity of the PCM system was not utilised.

\subsection{Daily Average Cooling Efficiency}

The daily average cooling efficiency (DACE) was calculated to give a representation of the system's ongoing operational efficiency under the test conditions. It has been calculated following an equivalent method to the European Seasonal Energy Efficiency Ratio (ESEER) [23] which quantifies the effective energy out, divided by the input energy. The figure is akin to the coefficient of performance (COP) and energy efficiency ratio (EER) figures for heat pumps; which each quantify the ratio of useful output to energy input [24]. The greater the ESEER, the more efficient the system is. As a comparison the AC system alone operates an EER (for cooling) of 3.04, whilst 
Monodraught's Cool-Phase system has an ESEER of 7.3. Due to the limited time period and conditions tested

2 there was insufficient data to calculate the ESEER, therefore the DACE was calculated.

\subsubsection{DACE Calculation Method}

$$
D A C E=\frac{\text { Useful Cooling }}{\text { Energy Consumed }}
$$

4

5

6

7

The (DACE) was calculated based on equation (1) above. The measure of energy efficiency was calculated based on the useful cooling ( $\mathrm{kWh}$ ) of the active thermal mass system, divided by energy consumed ( $\mathrm{kWh}$ ) during occupied periods (eight hours per day) [24]. The useful cooling was calculated from the component equations (2) to (3). Energy consumed was read daily from energy meters monitoring the AC and fan equipment.

$$
\begin{gathered}
D A C E=\frac{\sum q_{\text {slab }}+\sum q_{P C M}+\sum q_{\text {air }}-\sum Q_{\text {wall transfer }}}{\sum Q_{A C}+\sum Q_{\text {fan }}} \\
q_{\text {slab }, j}=m_{\text {slab }} c_{p, \text { slab }}\left(\bar{T}_{\text {slab }, j}-\bar{T}_{\text {slab }, i}\right)
\end{gathered}
$$

8 The slab useful cooling component $\left(q_{s l a b}\right)$ at time, $\mathrm{j}$, was calculated from equation (3). The temperature of the entire slab has been approximated equal to the average slab temperature, measured at a depth of 50mm from the soffit surface by nine embedded type-K thermocouples.

$$
q_{\text {air }, j}=\dot{m}_{\text {air }} c_{p, a i r}\left(\bar{T}_{\text {room }, j}-T_{\text {air inlet }, i}\right)
$$

11 The air useful cooling component ( $q_{\text {air }}$ ) at time, j, was calculated from equation (4), where the mass flow rate was calculated from equation (5). The temperature difference was based on the average room temperature, at time $\mathrm{j}$, and the slab inlet air temperature from the previous time step, i.

$$
\dot{m}_{\text {air }}=\rho_{\text {air }} D v
$$

14 Where applicable, The PCM useful cooling component ( $(\mathrm{P} P \mathrm{P}$ ) was a function of the PCM latent and sensible cooling loads, the PCM mass and the PCM temperature between time $\mathrm{j}$ and $\mathrm{i}$, as shown in equation (6).

$$
q_{P C M, j}=m_{P C M} c_{e f f}\left(T_{P C M, j}-T_{P C M, i}\right)
$$


1 To approximate the combined cooling load, effective heat capacity $\left(\mathrm{C}_{\mathrm{eff}}\left(\mathrm{T}_{\mathrm{PCM}, \mathrm{i}}\right)\right)$ figures were calculated at half

2 degree increments, based on physical properties of the installed PCM using the Gausian equation below [25].

3 Inputs for each physical property can be found in Table 7.

$$
c_{e f f}\left(T_{P C M, i}\right)=c_{S}+a e^{-0.5\left(\frac{T_{P C M, i}-T_{m}}{b}\right)^{2}}
$$

4 To account for chamber heat loss, heat transfer through the chamber wall was calculated, $Q_{\text {wall }}$ transfer, based on

5 the wall properties and ambient and average room temperature differentials (equation (8)).

$$
Q_{\text {wall transfer }, i}=U_{\text {wall }} A_{\text {wall }}\left(T_{\text {amb }, i}-\bar{T}_{\text {room }, i}\right)
$$

6 The figures, $Q_{A C}$ and $Q_{f a n}$, on the bottom of equation (2) were measured during the experiments using energy

7 meters. Each cooling component was summed throughout the occupied hours of the test; therefore the DACE

8 figure represents an occupied efficiency only. Table 7 details the inputs used throughout the analysis.

\begin{tabular}{|c|c|c|c|}
\hline Symbol & Term & & Units \\
\hline$m_{\text {slab }}$ & Mass of Slab & 1269.8 & $k g$ \\
\hline$c_{p, s l a b}$ & Concrete Specific Heat & 0.9 & $\mathrm{~kJ} / \mathrm{kgK}$ \\
\hline $\bar{T}_{s l a b, j}$ & Average Slab Temperature & time dependant, measured & ${ }^{\circ} \mathrm{C}$ \\
\hline $\bar{T}_{\text {slab }, i}$ & & variable & \\
\hline$\rho_{\text {air }}$ & Air density & 1.2 & $\mathrm{~kg} / \mathrm{m}^{2}$ \\
\hline$D$ & Outlet Diameter & 0.125 & $m$ \\
\hline$v$ & Air Velocity at Outlet & 2.5 & $\mathrm{~m} / \mathrm{s}$ \\
\hline$c_{p, \text { air }}$ & Air Specific Heat & 1.005 & $\mathrm{~kJ} / \mathrm{kgK}$ \\
\hline$m_{P C M}$ & Mass of PCM & 7.5 & $k g$ \\
\hline$c_{e f f}\left(T_{P C M, i}\right)$ & Effective Heat Capacity & see Figure 4.5 & $\mathrm{~J} / \mathrm{kgK}$ \\
\hline$c_{S}$ & Heat Capacity in Solid State & 1.9 & $\mathrm{~kJ} / \mathrm{kgK}$ \\
\hline$a$ & Latent Heat Factor & 164.6 & $\mathrm{~kJ} / \mathrm{kg}$ \\
\hline
\end{tabular}

Table 7 - Equation Inputs 


\begin{tabular}{|c|l|c|l|}
\hline$T_{P C M, i}$ & PCM Temperature & time dependant, measured & ${ }^{\circ} \mathrm{C}$ \\
$T_{m}$ & Melt Temperature & variable & \\
$b$ & Melting Width Factor (Standard & 24.5 & ${ }^{\circ} \mathrm{C}$ \\
& Deviation, Function of Purity) & 2.5 & ${ }^{\circ} \mathrm{C}$ \\
$U_{\text {wall }}$ & Heat transfer coefficient & 0.65 & $\mathrm{~W} / \mathrm{m}^{2} \mathrm{~K}$ \\
$A_{\text {wall }}$ & Area of chamber wall & 17.64 & $\mathrm{~m}^{2}$ \\
$T_{\text {amb,i }}$ & Ambient Temperature & time dependant, measured & ${ }^{\circ} \mathrm{C}$ \\
$\bar{T}_{\text {room }, i}$ & Average Room Temperature & variable & ${ }^{\circ} \mathrm{C}$ \\
\hline
\end{tabular}

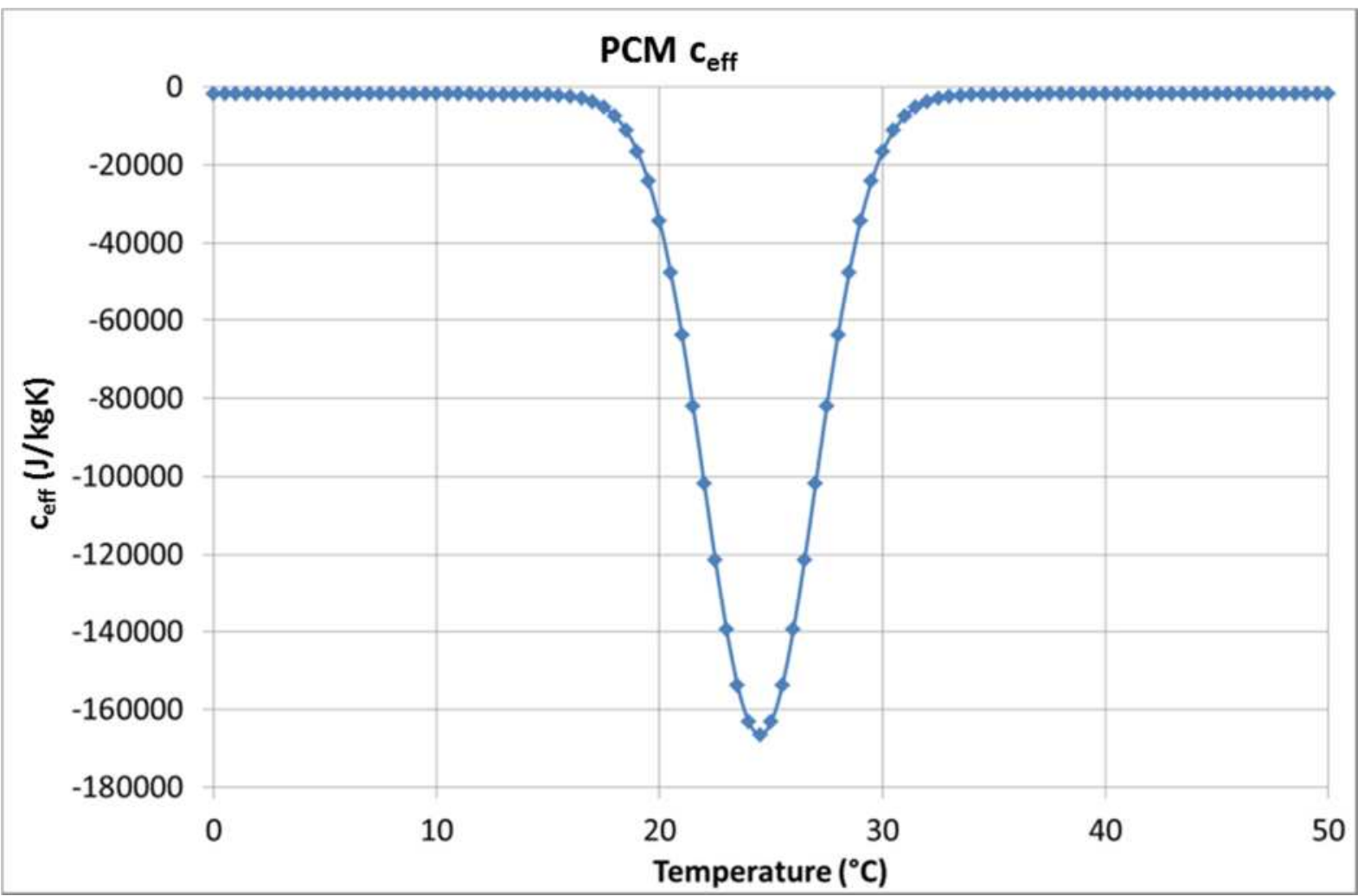

Figure 4.5 - Effective Heat Capacity for the installed PCM over a 0 to $50^{\circ} \mathrm{C}$ temperature range

Table 8 - DACE figures under peak and diurnal swing conditions

\begin{tabular}{|c|c|c|c|c|c|c|c|}
\hline Room & $A$ & VHC & VPHC & VHC & VPHC & VHC & VPHC \\
\hline Occupied & & Peak & Peak & Diurnal & Diurnal & Fixed & Fixed \\
\hline Totals & Units & Period & Period & Swing & swing & Occupancy & Occupancy \\
\hline
\end{tabular}




\begin{tabular}{|c|c|c|c|c|c|c|c|}
\hline Occ. Hours & Hours & 40 & 40 & 24 & 24 & 18 & 18 \\
\hline$q_{s l a b}$ & $k W h$ & -2.6 & 0.1 & 3.6 & 3.4 & 2.8 & 2.8 \\
\hline$q_{P C M}$ & $k W h$ & - & 0.2 & - & 1.6 & - & 1.6 \\
\hline$q_{\text {air }}$ & $k W h$ & 2.5 & 2.8 & 0.2 & -0.04 & -1.0 & -1.0 \\
\hline$Q_{\text {wall transfer }}$ & $k W h$ & 8.3 & 9.4 & 6 & 6.1 & 3.8 & 3.9 \\
\hline$Q_{A C}+Q_{f a n}$ & $k W h$ & 16.2 & 20.9 & 4.4 & 4.2 & 0.6 & 0.6 \\
\hline A: DACE & & 0.51 & 0.60 & 2.23 & 2.63 & 9.33 & 12.17 \\
\hline A-B: DACE & & -2.79 & -2.44 & 0.46 & 0.86 & - & - \\
\hline
\end{tabular}

1 Table 8 displays the components and DACE figures for the thermal mass systems under peak period, diurnal

2 swing and fixed occupancy conditions. The occupied totals have been converted into kWh from W based on the duration of occupied hours for each respective investigation. The DACE figures have been calculated using equation (2).

The VPHC system demonstrated greater DACE than the VHC system, an improvement of 0.4 under diurnal swing conditions. This was due to the additional thermal mass offering additional useful cooling during the daily 'occupied' period. This improvement represents an $18 \%$ increase in energy efficiency performance, from an addition of $12.5 \%$ thermal capacity.

Under fixed occupancy conditions the AC onset temperature of $24^{\circ} \mathrm{C}$ was removed, therefore the energy input $\left(Q_{A C}+Q_{f a n}\right)$ was made up solely of the fan power. The great reduction in energy input resulted in a significant increase in DACE. The fixed occupancy figure represents the efficiency possible if the system follows a control strategy capable of alleviating backup AC usage. The VPHC performance improvement, over the VHC system under fixed occupancy conditions, represents a 30\% gain. A DACE figure for Room B during the fixed occupancy test was not possible since there was no energy input, since no cooling system was in operation. The fixed occupancy figure does not take into account any pre-cooling or subsequent night cooling required to recharge for the next 'occupied' period. increased usage of the PCM latent heat storage available. During the diurnal swing conditions the PCM A and 
PCM B bulk temperatures reached a maximum of 25.4 and $22.9^{\circ} \mathrm{C}$ respectively. Under fixed occupancy conditions the same readings reached a maximum of 29.4 and $25.3^{\circ} \mathrm{C}$ respectively. This increase in temperature under the latter conditions demonstrates a complete usage of the latent capacity in PCM A, and greater usage of the latent capacity available in PCM B. Further optimisation to ensure year round usage of available latent capacity within the room operation temperature envelope will improve energy savings and the energy efficiency of the systems.

\section{Conclusions}

Thermal comfort and energy saving benefit of hollow core system was improved by the addition of active PCM thermal mass, avoiding the inhibiting effects of poor PCM thermal conductivity observed in [21]. Under peak period conditions where no free night cooling was available the active PCM addition was unable to reduce energy usage. AC backup was required to maintain comfort conditions.

After eight hours of fixed occupancy conditions the VPHC system saved $1.3^{\circ} \mathrm{C}$ more than the VHC system, against the reference chamber (Room B) temperatures. During diurnal swing testing the VHC and VPHC registered daily average cooling efficiency (DACE) figures of 2.2 and 2.6 respectively, suggesting an energy efficiency benefit when sufficient free night cooling is available. Under fixed occupancy conditions the VHC and VPHC DACE was 9.3 and 12.2 respectively, highlighting the benefit of minimising $A C$ and fan usage, whilst maximising latent thermal energy storage.

On an energy-saving level the VPHC system saved $0.1 \mathrm{kWh}$ per day more than the VHC system under diurnal swing conditions. Under peak period conditions the VHC and VPHC systems used 1.0 and $0.8 \mathrm{kWh}$ per day more than the reference chamber (Room B). The thermal mass chamber (Room A) used more energy under these conditions due to the absence of free night cooling. Thus the thermal mass no longer cooled the space, but heated it, requiring additional cooling from the backup AC system.

Overall the VPHC system offered energy savings in two out of the three conditions tested. The additional thermal mass did not mitigate AC usage during peak periods, however saved energy when free cooling was available (96\% of the time in a European climate [13]). Further development of accompanying control strategies that minimise fan and AC energy use will improve savings further. Additionally, optimisation of the PCM system 


\section{Acknowledgements}

This research has been supported through an Innovate UK grant led by industrial partner, Actimass Ltd.

\section{References}

1. International Energy Agency (IEA), Energy Technology Perspectives. 2014.

2. Wade, J., Pett, J., Ramsay, L.,, Energy efficiency in offices: Assessing the situation. The Association for the Conservation of Energy, 2003.

3. Davey, E., The Energy Efficiency Strategy: The Energy Effciency Opportunity in the UK, D.o.E.a.C. Change, Editor. 2012.

4. Lehmann, B., V. Dorer, and M. Koschenz, Application range of thermally activated building systems tabs. Energy and Buildings, 2007. 39(5): p. 593-598.

5. Winwood, R.B., R. and R. Edwards, Advanced fabric energy storage I: Review. BUILDING SERVICES ENGINEERING RESEARCH TECHNOLOGY, 1997. 18(1): p. 1-6.

6. $\mathrm{Xu}, \mathrm{X}$., et al., Research and application of active hollow core slabs in building systems for utilizing low energy sources. Applied Energy, 2014. 116(0): p. 424-435.

7. Olesen, B.W. and K.C. Parsons, Introduction to thermal comfort standards and to the proposed new version of EN ISO 7730. Energy and Buildings, 2002. 34(6): p. 537-548.

8. Ren, M. and J. Wright, A ventilated slab thermal storage system model. Building and Environment, 1998. 33(1): p. 43-52.

9. Barton, P., C. Beggs, and P. Sleigh, A theoretical study of the thermal performance of the TermoDeck hollow core slab system. Applied Thermal Engineering, 2002. 22(13): p. 1485-1499.

10. Green, N., Characterising the thermal energy transfer within a ventilated hollow core slab system. 2010, University of Bath: Bath.

11. Winwood, R., R. Benstead, and R. Edwards, Advanced fabric energy storage IV: Experimental monitoring. Building Services Engineering Research and Technology, 1997. 18(1): p. 25-30.

12. Winwood, R., R. Benstead, and R. Edwards, Advanced fabric energy storage II: Computational fluid dynamics modelling. Building Services Engineering Research and Technology, 1997. 18(1): p. 7-16.

13. Artmann, N., H. Manz, and P. Heiselberg, Climatic potential for passive cooling of buildings by nighttime ventilation in Europe. Applied Energy, 2007. 84(2): p. 187-201.

14. Whiffen, T.R. and S.B. Riffat, A review of PCM technology for thermal energy storage in the built environment: Part II. International Journal of Low-Carbon Technologies, 2012.

15. Ling, T.-C. and C.-S. Poon, Use of phase change materials for thermal energy storage in concrete: An overview. Construction and Building Materials, 2013. 46(0): p. 55-62.

16. Hawes, D. and D. Feldman, Absorption of phase change materials in concrete. Solar Energy Materials and Solar Cells, 1992. 27(2): p. 91-101.

17. Lee, T., et al., Control aspects of latent heat storage and recovery in concrete. Solar energy materials and solar cells, 2000. 62(3): p. 217-237.

18. Bentz, D.P. and R. Turpin, Potential applications of phase change materials in concrete technology. Cement and Concrete Composites, 2007. 29(7): p. 527-532.

19. Zhang, D., et al., Development of thermal energy storage concrete. Cement and concrete research, 2004. 34(6): p. 927-934.

20. Hunger, M., et al., The behavior of self-compacting concrete containing micro-encapsulated Phase Change Materials. Cement and Concrete Composites, 2009. 31(10): p. 731-743. 
21. Pomianowski, M., P. Heiselberg, and R.L. Jensen, Dynamic heat storage and cooling capacity of a concrete deck with PCM and thermally activated building system. Energy and Buildings, 2012. 53(0): p. 96-107.

22. CIBSE, The Limits of Thermal Comfort - Avoiding Overheating in European Buildings - CIBSE TM52: 2013. 2013, CIBSE.

23. Monodraught Ltd, Cool-Phase: Low energy cooling and ventilation system. 2014.

24. Butcher, K.J., CIBSE Guide F- Energy Efficiency in Buildings (3rd Edition). 2012, CIBSE.

25. Darkwa, K. and P.W. O'Callaghan, Simulation of phase change drywalls in a passive solar building. Applied Thermal Engineering, 2006. 26(8-9): p. 853-858. 